\title{
Let us sensitise gender issues with basic question, "What do we get from women empowerment?"
}

\author{
D. Tamilarasu ${ }^{1}$ \\ ${ }^{1}$ Asst. Professor cum Asst. Director, Center for study of social exclusion and inclusive policy, Manonmaniam \\ Sundaranar University, India
}

\begin{abstract}
Inorder to better the situational reality of women, several efforts are taken from international to local level. Existing social realities of women shows that those measures are not adequate enough and match up the desired outcomes. Sensitisation on various gender issues is also used as one of the efforts to address the problems faced by women in Society. Paper intends to take up the method of sensitisation but with a difference. Numerous debates and research prevails on the issue of 'women empowerment'. Our consciousness aware of those issues pertaining to gender but may be due to obsession of our consciousness most often with utilitarian attitude; the consciousness doesn't get attached to the issue. But asking the basic question, 'What is in women empowerment' may trouble the consciousness and has the possibility to open it up. This question can also satisfy our prevailing predominant utilitarian consciousness which requires the answer for, 'What do we get from women empowerment?', 'whether it benefits me in anyway'. Here, the paper addresses the basic questions and the answer is compiled with sufficient logical arguments supported with empirical data. Thus, the paper attempts to sensitise that women empowerment is not merely supplement, but inevitable for the holistic empowerment of the society.
\end{abstract}

Keywords- basic question, necessity of women empowerment, Social realities of women, Sensitisation, utilitarian consciousness

\section{Introduction}

Women exclusion exists in the long history of human society. It is universal irrespective of any differences like caste, class, creed, ethnic group, religion etc. Injustice heaped on women was recognized only in the later part of the history. It was due to the culmination of various factors such as intellectual discourse, social movements, notable historical events like industrial and political revolutions, voice of oppressed as an outcome of continued sufferings and the like. Universal declaration of human rights in 1948 embedded with implicit notion of women rights. In most of the democratic nations, many of the women rights were realized in principle and enforced in social policies and social legislations. But, to establish society ridden with gender justice in reality becomes toughest challenge to the nations. So, it stresses that effort has to be taken from International to local level. At international level, some of the significant events pertaining to women issue are: U.N. Economic and Social Council to promote the rights of women in political, economic, civil, social, and educational fields established the commission of the status of women in 1946. Declaration of UN decade for women (1976 to 1985) and focus on the agenda of women empowerment in fourth world conference on women known as Beijing platform for Action in 1995.Convention on the elimination of all forms of discrimination against women (CEDAW) adopted in 1979 by the UN General Assembly, is often described as an international bill of rights for women; UN conventions on the rights of child in 1990 as complementary effort; UN Declaration on the elimination of violence against women in 1993, establishment of special entity for women such as UN women by incorporating the previously established organization like UNIFEM-United Nations entity for Gender equality and the empowerment of women, DAW-Division for advancement of women, UNINSTRAW- United Nations International Research and Training Institute for the Advancement of Women.[1] UN's Millennium Development goals (MDGs) by incorporating the targets for women issues, peaks all the effort.

At national level, there are several efforts taken in tune with international conventions and also of own, relevant to the Indian context. Social legislations such as abolition of sati, child marriage restraint act, Marriage acts, Dowry prohibition, Equal property rights, indecent representation of women, Domestic violence act are some of the efforts. Establishing separate ministry for women and child welfare leads to creation of various welfare policies; creation of national policy for women empowerment; reservation for women in local bodies are other dimensions of the effort. Simultaneously, five year plans goes on to devise the agenda and allocate funds for women related issues. 


\section{Social realities}

In spite of all these efforts, social reality is,

Of the 776 million illiterate adults worldwide, two thirds are women.

Women continue to die of pregnancy-related causes at a rate of about one per minute. (UNFPA- UN population fund, UNICEF- UN children's fund) [2].

Six out of ten poorest inhabitants of the world are female. (UNDP- UN Development Programme) [3]

Lowest female sex ratio is one of the common social menaces throughout the world.

\section{Indian Social reality shows,}

India occupies $129^{\text {th }}$ rank in terms of Gender related development index (GDI) out of 187 countries according to UN human development report 2011.[4]

A recent study of the world economic forum titled "Global Gender Gap Report 2012" calculated the Gender Gap index in which India ranks 105 among 135 countries. It was at $95^{\text {th }}$ rank in 2006 report. So, women in India lack empowerment in various spheres. This also shows that the efforts are not able to match up in changing the worse realities of women.

As per Census 2001, Indian female population consists of $14.68 \%$ main workers, $10.95 \%$ marginal workers and the remaining $74.37 \%$ non workers. [5]

The proportion of Crime against women to total IPC crimes is showing an increasing trend during 2001-2006. This statistics not includes the unreported violence against women. Among the Crimes committed against women in 2006, the crimes of torture and molestation together constitute 60.53\%. [5]

Except in few states, Sex ratio is in constant declining trend in India.[6]

Beside these empirical data, there are many worse social realities of women, which we can perceive through common sense in our day today life.

\section{Significance And Objectives Of The Paper}

Despite of all efforts above given bitter realities still persist. So, these efforts have not produced any desired changes in the conditions of women in reality. It leads to the question, 'Why is it so?' One possible answer is that inadequacies of these efforts need to be identified and made closer to the situational reality, if necessary, more such efforts has to be devised and properly implemented. Howsoever and whatsoever the answer may be, all of such answer can be based on and moves towards the objectives of 'Women Empowerment'. Women need empowerment. Before going into the debates and research on ways and the process of women empowerment as probed most often, first and foremost fundamental question needs to be understood, realized and agreed upon: What do we get from women empowerment? What are the consequences if they are not empowered? What is so special and unique in women empowerment? How it differs and outweighs the benefits of men empowerment or men development or development in general? All are similar questions but asked in a different way to create sensitisation of the question. However, the questions seem to be very simple and basic. But, many a times, the consciousness forgets the basic and so it doesn't get attached or felt the necessity of women empowerment.

Imaginative story is narrated here to enlighten the idea. A drunken man marveled at caterpillar traits of walking with thousands of legs and asked how it is able to do so and which leg it would keep first and in forward position. Caterpillar suddenly goes blurred and struck up to encounter this 'never thought of' basic question. Caterpillar tries to remind and made an attempt to find which leg it usually keeps forward. This new consciousness on its routine unconscious activity made it uneasy to answer the basic question. Doubts emerged as like disturbed honey bees from their bee comb. The mind of caterpillar becomes like misty clouds that covers the sky. This question troubled it very much, to move further. It is in blurred, confused and in awkward state of mind. Like that of caterpillar, many times our consciousness troubled to encounter basic questions as given here like 'what do we get from women empowerment?'

So, sometimes the consciousness forgets the basics and wonders why there are so much hues and cries on the issues of women rights, women development. If it says that it knows that there are junks of policies, discourses, legislations, researches, initiatives, protest, controversies on women development. Extensively, there is awareness of those junks but why should one care about women empowerment. Most of the beings in one or the other with their own notions strive to develop for various reasons. Men are very much involved in the process. It is said that women are not able to or hindered or alienated from the process of development.

Though answer for this basic question is prevalent in scattered form in various literatures which includes UN documents and related others but the way the issue is questioned and the manner in which it is answered and compiled here, makes the paper as unique from the existing literatures. Factual arguments in the prevailing literatures supports the theme of the paper is not necessarily get into common man's consciousness and there exists lacunae in sensitizing the issue. Consciousness of human beings of the present society is most often orient towards individualism, and so it is obsessed with utilitarian attitude, such consciousness tends to be sensitised 
by the issue, only if the issue more likely hurts in person but not otherwise. If we say or aware of that social exclusion of women is hurting women; men and women, state and related others may not get attached to it. If we say further, it also hurts us in many ways, then we are ready to be in the process of sensitisation or we said to be sensitised. In order one to get attached and feel the necessity and urgency of women empowerment, basic question is answered in the paper to remind and make sensitization on the necessity of women empowerment. Simultaneously, the paper attempts to prove that women empowerment is not supplement, but inevitable for holistic development of society.

\section{Methodology}

Argument of the paper is constructed with the original idea in synthesis with relevant literatures and policy documents. Most of the arguments of the paper are supported with the relevant secondary data as empirical facts.

\section{V. Conceptual Clarification}

The concept of 'Women Development' has undergone various evolutionary stages. Initially, women development is mostly associated with 'Welfare approach' in which women are considered as passive recipients of the welfare measures provided by the state. It treats them as mothers and as a member of the family. By considering women as active participants in development process, the paradigm 'Women in Development' gives utmost importance to economic development of the women but lacunae prevails in not explaining gender relations and gender identity. It leads to the concept of 'Gender and Development' which gives primacy to the analysis of gender identity and social relations of gender in the discourse of women development. Simultaneously, in tune with these ideas, beside welfare approach as mentioned earlier, there are equity approach which intends to gain equity; anti-poverty approach focuses on providing income generation for poor women; efficiency approach is to ensure that development is made efficient and effective through women's economic contribution and very recent empowerment approach, needs following explanation as the concept is used in the paper.

It is very much narrower and incomplete if women development is confined merely to economic development alone as commonly understood. Hence, usage of concept 'women empowerment' can be more encompassing, holistic and more relevant to theme of the paper. Furthermore, 'empowerment' approach is aimed at empowering women through greater self-reliance and internal strength. Enormous conceptual analysis has been done on those terminologies. World Bank's Sourcebook on Empowerment and Poverty Reduction has broad reference to empowerment as the expansion of freedom of choice and action, applies to women as well as other disadvantaged or socially excluded groups. However, empowerment approach in governmental plans and NGO is mostly used in the notion that empowerment starts with engaging or making them to create an opportunity of income generation and proceeds further to accrue the social, political and all other forms of empowerment. 'Empowerment' approach as a concept is used here in the notion of paying equal attention to all forms of empowerment i.e., social, political, cultural, educational, economic, psychological etc. It is understood that one form of empowerment can create cumulative consequences and leads to other forms of empowerment. For instance, If women is psychically empowered i.e., possessing strong personality. It is understood that she can also takes it to the level of social, cultural and even to economic empowerment. And also another extreme possibility is that economically empowered women i.e., she holds job but if she lacks psychological empowerment or social understanding, her economic empowerment may not take her to other domains of empowerment. Therefore, the concept of, 'Women empowerment' used in the paper refers to holistic and in encompassing manner. It also refers to the empowerment which has the capability to add upon other forms of empowerment. Women empowerment is inclusion of all empowering traits and exclusion of all disempowering factors. Thus, the concept in currency called 'Women empowerment' is well adequate and suits the theme of the paper.

\section{What do we get from women empowerment?}

The scope of the theme is very wider and so all of the outcomes of women empowerment are listed and discussed briefly, not intensively but with suitable empirical illustration. All of the following factors are mutually reinforcing and overlapping but their uniqueness makes it possible to separate each other.

IV.1.As a Human Right: Empower oneself for fulfilling their basic needs and also to the extent of enjoying the privileges as like that of others is human right. Irrespective of any differences like class, caste, gender, age, one has right to empower oneself. Therefore, Women has right to empower herself and participate in the development process. Women empowerment as like that of their counterpart sex is a human right. Factors which disempower, exclude and hinder women from the empowerment process, become violation of human right. Nation or any society that respects human rights of women, most likely they respect all other human rights. 
IV.2.As Social Justice: Society ridden with human right, equality, equity and solidarity is said to have Social Justice. Gender equality whether it is in the development process or in legislation or in any other case may be; is one of the components of Social Justice. Social justice is prelude to development and peace. Society lacking gender justice cannot be identified as society with social Justice. Thus, women empowerment is inevitable component of Social Justice.

IV.3.As Inclusive development: Inclusive development can be well understood with the reference to the concept of exclusion. In the context of development, certain people either intentionally or unintentionally, are excluded and most vulnerable to be excluded, from the process and outcomes of the development. Women are one of the social groups who are excluded or vulnerable to be excluded. Such exclusion results in various consequences as discussed in the paper. Men are the active and predominant participant of the mainstream development process whereas women are excluded from it. In order to have inclusive development process, women need to be included or integrated in the process and outcome of the development. So, women empowerment is necessary to achieve the state of inclusive development in any society. Inclusive society is path to establish society with just, order and progress.

IV.4.Welfare and development of children and other family members: 'Women empowerment' has cumulative positive consequences. Unlike men, identity of women is often portrayed as women in family or in group rather than women as an individual. Some of the feminist and other thinkers not favor such identity for various justifiable reasons. This kind of identity also has some practical utility but this statement not subscribe to the idea that women has to suppress or sacrifice her individual identity. Children's life and also other family members are more interconnected and revolve around her life. Simultaneously, her life also revolves around them. Women as mother have inevitable role in upbringing her Children. She is also engaged in all other domestic work of her family. It becomes negative if it curtails her likeness to involve in her desired work and if her task associated in children's life and other family members is not recognized and considered as unproductive. She plays prominent role especially in nurturing the child's life in terms of health, education, cognitive development, psychological traits and so on. That's the reason, policy documents of UN and others adopts integrated approach in the issues related to women and children by understanding the reality of inseparability of their life. 'Women empowerment' cannot merely consider as individual empowerment and that's how it differs from men development. Following fact supports it.

World Food Programme found that when girls and women earn income, they reinvest $90 \%$ of their income in their families. For example, providing credits to women SHGs are due to the fact that male members of family especially people below poverty line are habituated to alcoholism and other related factors, thus, those male members are not beneficial to their family. It pushes the women to toil themselves in various other work apart from their traditional role of taking care of their family. Howsoever and whatsoever the reason is citied, whether it is due to traditions, inherent traits of female, their habit of saving and utilizing the money properly, culturally imbibed quality and others, women are more interested and feel responsible in enhancing the income and spending for the welfare of the family especially children. She is ready to sacrifice her own interest and welfare for sake of other family members. Various statistics proves that the region possessing positive indicators on women most probably have similar trend of positive indicators on children and family. Thus, providing opportunity to empower women, economically, politically, psychologically ends up in chain of positive consequences to the family and society. Following empirical data proves the argument,

Best ranked Countries of CDI \& GDI

\begin{tabular}{|l|l|l|}
\hline CDI Rank & Country & GDI rank \\
\hline 1 & Japan & 13 \\
\hline 2 & Spain & 12 \\
\hline 3 & Canada & 4 \\
\hline
\end{tabular}

\section{Lowest ranked Countries on CDI \&GDI}

\begin{tabular}{|l|l|l|}
\hline CDI Rank & Country & GDI rank \\
\hline 137 & Niger & 155 \\
\hline 136 & Sierra Leone & 157 \\
\hline 133 & Angola & 142 \\
\hline 112 & India & 113 \\
\hline
\end{tabular}

Source: Child Development Index (CDI-2000-2006) from Save the Children, UK and Gender Development Index (GDI) from UNDP's Human Development Report of 2007/2008.

It is inferred from the above tables that Countries with higher rank of CDI also has equivalent or best ranking in GDI and vice versa. The report of 'Save the Children' suggests 'women empowerment' as one of the effective tool for child development.

IV.5.As human development: The concept of 'social development' and 'human development' is interrelated, mutually influencing and overlapping in nature but can be differentiated as the perspective of capacity 
enhancement of human being as human development and collectivistic improvement of community is manifested as Social Development. First and foremost provider of 'Socialisation' and 'human resources developer' is woman in the role of 'mother' to her child. Empowered women as mother can be an effective provider of 'Socialisation' and 'Human resources developer' which any other institution may not be able to match up with her. Nurturing the child i.e., future member of the human society, is noble task carried out by women as mother. If it is considered that female has certain inborn and inalienable feminine characteristic traits, she said to have unique role in psychological empowerment of the child. A popular quote which is adequate enough to convey the importance of women in human development, "if you educate a men, you are educating an individual but if you educate a women, it is like educating a whole family". Following can be suitable illustration to prove the inseparability of women empowerment and human development.

IV.6.Rank of nations in human development and Gender inequality Index based on UN HDR report of 2011: Very high, high, medium and low development are the categories under which various nations are ranked. Sample of top ranking 2 countries among each categories are used here, inorder to identify how far its HDI and GII ranking are closer. Whether ranking of both form of index has any extreme variations?

Very high human Development nations

\begin{tabular}{|l|l|l|}
\hline $\begin{array}{l}\text { HDI } \\
\text { Rank }\end{array}$ & Country & GII Rank \\
\hline $\mathbf{1}$ & Norway & $\mathbf{6}$ \\
\hline $\mathbf{2}$ & Australia & $\mathbf{1 8}$ \\
\hline
\end{tabular}

Medium human Development Nation

\begin{tabular}{|l|l|l|}
\hline HDI Rank & Country & GII Rank \\
\hline $\mathbf{9 5}$ & Jordan & $\mathbf{8 3}$ \\
\hline $\mathbf{9 6}$ & Algeria & $\mathbf{7 1}$ \\
\hline
\end{tabular}

High Human Development Nations

\begin{tabular}{|l|l|l|}
\hline HDI Rank & Country & GII Rank \\
\hline 48 & Uruguay & $\mathbf{6 2}$ \\
\hline $\mathbf{5 0}$ & Romania & $\mathbf{5 5}$ \\
\hline
\end{tabular}

Low human Development Nations

\begin{tabular}{|l|l|l|}
\hline HDI Rank & Country & GII Rank \\
\hline 143 & Kenya & 130 \\
\hline 145 & Pakistan & 115 \\
\hline
\end{tabular}

From the above tables, it is not only inferred that there are no extreme variations in ranking of HDI and GII but also has closer and more or less similar trend of ranking of HDI and GII. It is not possible to find a nation with higher gender inequality to achieve higher ranking in human development. GII and HDI are mutually reinforcing each other. Commonsense is enough to understand that women empowerment is a part of Human Development. But, the argument which needs to be realised here is that women empowerment or reducing the Gender inequalities can accelerate the human development of the country.

IV.7.Environmental Conservation: There are thinkers who believe that women and men have different traits. Some are mutually exclusive as some are mutually inclusive traits. These arguments have the base on psychological foundations of natural traits of personalities. It also goes against or not completely accepts the sociological based arguments of constructed gender identity and social reality. There are unique qualities identified or associated with both male and female. Thus, this uniqueness makes the equality to comprehend as substantive equality. Traits such as soft, caring, emotional, submissive, collective-orientation, protective are said to be predominant in female. Economic development especially lead by aggressive capitalist policy unleashed with the help of huge machineries and technology, more rationalized system of economic activities, market determined economy and related others become more detrimental to environment. Environmental degradation becomes one of the darker sides of current globalised aggressive economic policy. Thinkers who argue that female characteristic traits have something to do with environmental conservation are referred as 'Ecofeminist'. Environmental degradation is the cause of prevailing male dominated aggressive capitalist economic policy. If development discourse is more oriented and incorporative towards the active female participant economy, there is more probability to reduce the environmental degradation. Female traits ridden economy can also diminish other ill-effects of male dominated economy. While changes in the environment affect everyone, they affect men and women differently. Women's and girls' traditional responsibilities as food growers, water and fuel gatherers, and caregivers connect them intimately to available natural resources and the climate, making them more vulnerable to environmental hardships.(UNDP). Following facts strengthens this argument,

1)A special Eurobarometer survey on attitudes towards climate change in 2009 found that women more often than men reported to have undertaken personal actions such as recycling, saving water and energy at home and using environmentally-friendly transports.[7].

2) Social movements such as Chipko movement are substantial proof for the argument of 'Ecofeminst'.

IV.8.For Sustainable Development: Previous topic of the paper covered one of the component of sustainable Development i.e., environmental sustainability. 'Sustainable Development' defined as, 'the development that 
meet the needs of the present without compromising the ability of future generations to meet their own needs'. Any form of development whether it is economy, social or cultural spheres cannot be sustainable without equal and just participation of other half of the sections of human population. Sustainable development incorporates the inter-generational and intra-generational Justice. Both form of justice by analysing in terms of gender can identify the necessity of women empowerment for the sustainable development. [8]. Sustainable development and women empowerment are mutually influential. This view also expressed by UNIFEM (UN Women). These can be empirically proved if we consider the examples of states like Kerala where the practice of sustainable development can be traced to certain extend.

IV.9.Economic development: Women empowerment and economic development is closely associated. There are two dimensions on which the issue can be discussed. One is economic empowerment of women, considered as prelude to their empowerment in all other spheres of life. Lack of income generating opportunity create and aggravate the gender inequality. Economic empowerment may also leads them to face the problem of role conflict, stress in managing life-work balance and sometimes leads to the consequences like divorce as visible in urban scenario. These negative consequences necessitate the importance of other forms of empowerment. Second dimension is that economic empowerment of women contributes to the strength and growth of national economy. Following are the empirical data to prove the argument.

According to the estimates of United Nations Economic and Social Commission for Asia and the Pacific (UNESCAP), the region loses up to $\$ 47$ billion in output each year due to lack of female participation in labor markets.

Studies show that closing the gap between male and female employment rates can boost gross domestic product (GDP) in many countries-for example it can advance American gross domestic product (GDP) by 9 per cent, Eurozone GDP by 13 per cent and Japanese GDP by 16 per cent.(http://www.unwomen.org/the-unitednations-conference-on-sustainable-development-rio20/facts-and-figures/) World economic forum in its first attempt study (2005-Current updates of the study is not used in the paper since the data generated for more number of countries is complex to interpret and requires detailed explanation) ranked different countries of the world based on gender gap. Nordic countries such as Sweden, Norway, characterized by strong liberal societies with protection of minority rights and adequate welfare system occupies the top place, followed by 'Women friendly nations' such as New Zealand, Canada, UK. Several Eastern European and transition economies placed well among the top 25 and their wedding to socialist ideology can be easily identified as reason for their performance. India just stands above the conservative Muslim nations. Therefore, if the development is considered in the holistic sense, it can be inferred that the correlation of development and gender gap ranks shows that region with higher the gender gap more likely to have lower development and vice versa.

IV.10.As an antidote for many social problems and leads to Social Development: UN in co-ordination with world leaders after realising the pressing problems faced by the different nations of the world, adopted targets to reach, for the entire world community. These are referred as Millennium development goals.[9] There are eight MDGs as follows,

1. Eradicate extreme poverty and hunger, 2) Achieve universal primary education, 3). Promote gender equality and empower women, 4). Reduce child mortality, 5) Improve maternal health,6) Combat HIV / AIDS, malaria and other diseases, 7) Ensure environmental sustainability, 8) Develop a global partnership for development If there is some common solution to be identified and prescribed for all these problems, 'women empowerment' can be the one to reach all these MDGs set forth by United Nations. 'Women empowerment' is directly associated and easily identified as inevitable factor to reach the goals especially from $2^{\text {nd }}$ to $6^{\text {th }}$ goals. It also plays indirect role as well as direct consequences in some context to reach the other 3 MDGs. Mere common sense is enough to link these goals with women empowerment but considering the worse realities of the women, it appears, this kind of common sense is highly uncommon. This is all about tapping the dormant potentiality of other half sections of the human population. To find that numerous problems can be solved by single agenda i.e., 'Women empowerment' signifies the 'gender mainstreaming' of the development. Some of the facts to prove the argument are given as follows,

Gender inequality is a major cause and effect of hunger and poverty: it is estimated that 60 per cent of chronically hungry people are women and girls; 20 per cent are children under 5 years old. [10].

Giving women the same access as men to agricultural resources could increase production on women's farms in developing countries by 20 to 30 per cent. This could raise total agricultural production in developing countries by 2.5 to 4 per cent, which could reduce the number of hungry people in the world by $12-17$ per cent, or 100 to 150 million people. [11].

'Women empowerment' is an antidote for all other social problems such as Child marriage, unfavorable Sex ratio, Female infanticide, Dowry, Dowry-death, Domestic violence, population explosion, illiteracy, maternal mortality, nutritious deficiency, lack of health and sanitation and so on. Thus, empowered women have the potential to alleviate these social problems and thereby able to contribute towards social development. As most 
of the themes of MDGs are already briefly explained with suitable empirical facts in the paper, it is not necessary to elaborate the argument further in this regard.

IV.11.Peace: Considering the natural characteristic traits of women or feminine qualities, women are more easily suit to resolve the conflicts or to establish peace in Society. Statistical picture shows that women are meagerly engaged in institutionalized peace process. They can play crucial role in peace building process starting from family to International scenario. It is practically visible in some of the traditional societies of Asian countries, women have high tolerant attitude and shock observers of the family. They become the reason for preventing the escalation of violence in those families. If those women are raised to the power of decision making capacity, violence would end up not only against the women community and in family but also in entire society.

More participation of women in politics especially from grassroots level can bring tremendous change in aggressive muscle power violent ridden male dominated politics. Non-violent struggle is proved to be effective means for long lasting conflict resolution at many times in the history. Society constructed upon the foundation on the principle of non-violence is matured enough to resolve the conflict without eruption of violence. The principle of non-violence closely associated with feminine traits. If women are more engaged in politics, it gives rise to the emergence and spread of non-violent means to reach the objectives of politics. So, by such political participation of women, peaceful means are adopted for conflict negotiation to achieve long lasting peace as an end. Here, means and ends are the same, i.e., non-violence, in the case of women participation in politics. This kind of women participation also results in some of positive outcomes such as democratic governance.

Women are most easily victimized in the conflict zones or in post-conflict scenario. By engaging them in peace keeping operations in those situations prevents this kind of victimization of women. If a nation or society respects and protects the human rights of women, it is most probably a peaceful society.

Spiritualism which preaches peace to the society prescribes implicitly or explicitly like that of, imbibing of so called feminine qualities and to get rid of so called glorified masculine qualities. Inherently, it supports the idea of women potentiality in peace building process. It is unfortunate that Spiritualism, institutionalised as religion become the reason for some of the subjugation faced by women in society.

Some of the following events demonstrate the argument of linking women empowerment and peacemaking.

The CEDAW encourages increasing the presence of women in peacekeeping bodies and mainstreaming gender perspectives throughout peace-keeping operations with the intention of preventing discrimination against women within the host nation by peacekeeping operations.

Women's equal participation in all aspects of peace processes is emphasized in the Beijing platform for Action.

UN Security Council resolution 1325 passed on the $31^{\text {st }}$ October 2000 recognized that women world-wide are playing an active and positive role in conflict resolution and peace building.

\section{Conclusion}

Therefore, 'women empowerment' is not mere supplement, but inevitable and prelude to welfare and holistic development of any society. Factors and forces hindering, ignoring, underestimating 'women empowerment' can be easily diluted by sensitizing that even if we say it in the language of utilitarian perspective, there are multiple and chain of benefits accrued through 'women empowerment'. Expected outcomes of such sensitisation would be, for instance, Father attend to girl child's education, husband recognize the significant role of her wife in family, policy makers and state may be urged and pushed to give priority on 'women empowerment', empowered women is capable enough to fight against violence or injustice committed on her, empowered women can make use of their rights and most significant of all, empowered women and gender sensitised men can nurture the future progressive society with gender justice.

\section{References}

[1] www.unwomen.org

[2] Jensen, Lois, Women's \& Children's Rights: Making the Connection, Published by UNFPA and UNICEF, 2010.

[3] www.undp.org

[4] Human Development Report 2011, Sustainability and Equity: A Better Future for All, UNDP, USA

[5] Ministry of Women and Child Development, A Handbook of Statistical Indicators on Indian Women 2007, Government of India.

[6] http://wcd.nic.in/ (Ministry of Women and Child Development)

[7] http://ec.europa.eu/public_opinion/archives/ebs/ebs_322_en.pdf

[8] http://www.unece.org/fileadmin/DAM/oes/disc_papers/ECE_DP_2012-1.pdf (A discussion paper of UNITED NATIONS ECONOMIC COMMISSION FOR EUROPE Geneva, Switzerland)

[9] http://www.un.org/millenniumgoals/index.shtml

[10] World food programme, WFP Gender Policy 2009, policy, planning and strategy division, Italy.

[11] http://www.fao.org/docrep/013/i2050e/i2050e.pdf 